\title{
Reduction of Renal Uptake of Radiolabeled Octreotate by Amifostine Coadministration
}

\author{
Marleen Melis ${ }^{1}$, Roelf Valkema ${ }^{1}$, Eric P. Krenning ${ }^{1}$, and Marion de Jong ${ }^{1,2}$ \\ ${ }^{1}$ Department of Nuclear Medicine, Erasmus MC, Rotterdam, The Netherlands; and ${ }^{2}$ Department of Radiology, Erasmus MC, \\ Rotterdam, The Netherlands
}

\begin{abstract}
Megalin-mediated renal retention of radiolabeled somatostatin analogs may lead to nephrotoxicity during peptide receptor radionuclide therapy (PRRT). The cytoprotective agent amifostine protected rats from long-term nephrotoxicity after PRRT with ${ }^{177}$ Lu-DOTA,Tyr ${ }^{3}$-octreotate. This study describes the direct effect of amifostine on kidney and tumor uptake of ${ }^{111} \mathrm{In}$ DOTA,Tyr ${ }^{3}$-octreotate. Methods: In vivo biodistribution studies were performed using CA20948 tumor-bearing rats, with or without amifostine coadministration, via several routes. In vitro uptake was studied in somatostatin receptor-expressing CA20948 and megalin or cubilin receptor-expressing BN-16 cells, in the absence or presence of amifostine or its active metabolite WR-1065. Results: Coadministration of amifostine decreased renal uptake of radiolabeled octreotate in vivo, whereas tumor uptake was not affected. In agreement, amifostine and WR-1065 coincubation reduced uptake in BN-16 but not in CA20948 cells. Conclusion: Amifostine may provide renal protection during PRRT using somatostatin analogs, both by mitigation of radiation damage and the currently observed reduction of absorbed kidney radiation dose.
\end{abstract}

Key Words: amifostine; WR-1065; PRRT; kidney; tumor protection J Nucl Med 2012; 53:749-753 DOI: 10.2967/jnumed.111.098665

$\mathbf{P}$ atients with metastasized somatostatin receptor-overexpressing tumors can benefit significantly from peptide receptor radionuclide therapy (PRRT) using ${ }^{177} \mathrm{Lu}-$ or ${ }^{90}$ Y-labeled somatostatin analogs, for example, $\mathrm{Tyr}^{3}$-octreotate (1). However, megalin receptor-mediated reabsorption of radiopeptides in the renal proximal tubules may lead to long-term renal damage (2). Renoprotection by coinfusion of the cationic amino acids lysine and arginine is commonly applied, reducing renal uptake of radiolabeled somatostatin analogs by $40 \%(2,3)$. Kidney protection may also be achieved by mitigation of radiation-induced tissue damage by radioprotective drugs such as amifostine (3).

Received Sep. 26, 2011; revision accepted Jan. 31, 2012.

For correspondence contact: Marleen Melis, Erasmus MC, Department of Nuclear Medicine, 's Gravendijkwal 230, 3015 CE Rotterdam, The Netherlands. E-mail: m.melis@erasmusmc.nl

Published online Apr. 10, 2012.

COPYRIGHT @ 2012 by the Society of Nuclear Medicine, Inc.
The radical scavenger amifostine (Ethyol, WR-2721; MedImmune Oncology, Inc.) was developed by the Walter Reed Army Institute of Research as a radioprotective drug in case of nuclear war. It is approved by the Food and Drug Administration for application during radiotherapy (4) and chemotherapy (5) to protect healthy tissues such as kidneys, salivary glands, and bone marrow progenitor cells (6). Scavenging of free oxygen radicals was reported as a mechanism of action (4). Amifostine is converted into its active compound WR-1065 after dephosphorylation by alkaline phosphatase, which is present in, for example, arteriolar endothelium of various normal tissues and proximal tubular epithelium in the kidney (7). The molecular structures of amifostine and WR-1065 are shown in Figure 1, demonstrating structural resemblance with lysine at the $\mathrm{N}$-terminal end.

Intraperitoneal administration of amifostine protected rat kidneys from fibrosis and tubular atrophy beyond $150 \mathrm{~d}$ after external-beam irradiation (8). We previously reported that intravenous coadministration of amifostine, followed by 7 daily subcutaneous injections, also protected kidneys from long-term toxicity after internal irradiation by ${ }^{177} \mathrm{Lu}$-DOTA, $\mathrm{Tyr}^{3}$-octreotate (3). Non-tumor-bearing rats were studied; therefore, potential tumor protection against therapeutic effects of PRRT by amifostine could not be examined. The conversion of amifostine into WR-1065 is much higher in normal than in tumor tissues, because in normal tissues alkaline phosphatase activity in capillaries is high whereas in tumor tissues vascularization is abnormal, with low expression of alkaline phosphatase and a relatively low $\mathrm{pH}(9)$. Hence, attenuation of tumor therapy by amifostine is not expected; however, preclinical reports are ambiguous on this issue (9-11).

In the current study, we aimed to gain more insight into the renal protection mechanism of amifostine. In addition, we studied potential tumor protection by amifostine-that is, interference with tumor uptake of radiolabeled octreotate, both in vivo and in vitro. Amifostine was coadministered intravenously or subcutaneously with ${ }^{111}$ In-DOTA, $\mathrm{Tyr}^{3}$-octreotate to somatostatin receptor (sst)-expressing CA20948 tumor-bearing rats, routes also applied in patients. Uptake of ${ }^{111} \mathrm{In}$-DOTA, $\mathrm{Tyr}^{3}$-octreotate in the presence of amifostine and WR-1065 was examined in CA20948 and 


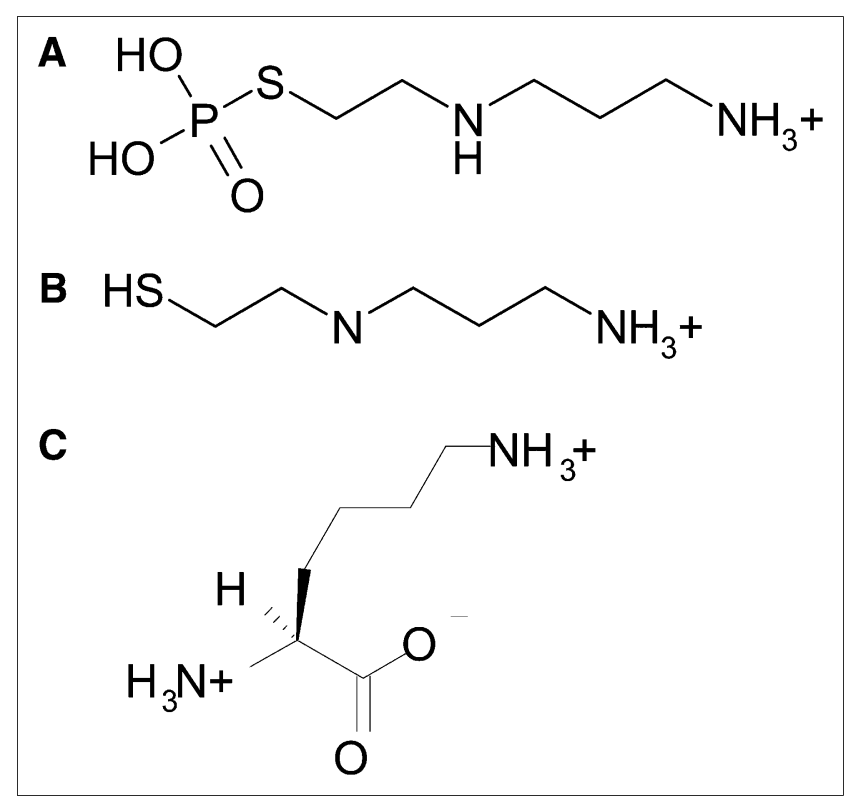

FIGURE 1. Molecular structures of amifostine, WR-1065, and lysine. (A) Amifostine = WR-2721 $=\mathrm{C}_{5} \mathrm{H}_{15} \mathrm{~N}_{2} \mathrm{O}_{3} \mathrm{PS}=\mathrm{H}_{2} \mathrm{~N}-\left(\mathrm{CH}_{2}\right)_{3}-\mathrm{NH}-$ $\left(\mathrm{CH}_{2}\right)_{2}-\mathrm{S}-\mathrm{PO}_{3} \mathrm{H}_{2}$; molecular weight $=214.2$. (B) WR-1065 = $\mathrm{C}_{5} \mathrm{H}_{14} \mathrm{~N}_{2} \mathrm{~S}=\mathrm{H}_{2} \mathrm{~N}-\left(\mathrm{CH}_{2}\right)_{3}-\mathrm{NH}-\left(\mathrm{CH}_{2}\right)_{2}-\mathrm{SH}$; molecular weight = 134.3. (C) Lysine $=\mathrm{C}_{6} \mathrm{H}_{14} \mathrm{~N}_{2} \mathrm{O}_{2}=\mathrm{H}_{2} \mathrm{~N}-\left(\mathrm{CH}_{2}\right)_{4}-\mathrm{CH}\left(\mathrm{NH}_{2}\right)-\mathrm{COOH}$; molecular weight $=142.2$.

$\mathrm{BN}-16$ cells, with $\mathrm{BN}-16$ cells as a model for renal uptake because of megalin expression.

\section{MATERIALS AND METHODS}

\section{Radionuclides, Peptide, and Chemicals}

${ }^{111} \mathrm{InCl}_{3}$ was purchased from Covidien. DOTA, $\mathrm{Tyr}^{3}$-octreotate and octreotide were supplied by BioSynthema. Radiolabeling of ${ }^{111}$ In-DOTA, Tyr ${ }^{3}$-octreotate was performed as described (12) at a specific activity of $50-80 \mathrm{MBq} / \mu \mathrm{g}$ for in vitro experiments and at $3 \mathrm{MBq} / 15 \mu \mathrm{g}$ or $3 \mathrm{MBq} / 0.5 \mu \mathrm{g}$ for in vivo studies.

Human serum albumin (HSA) kits (Vasculocis) were purchased from IBA Molecular Benelux and labeled with ${ }^{99 \mathrm{~m} T c}(10 \mathrm{MBq} / 2$ $\mathrm{mg} / \mathrm{mL})$.

Amifostine (Ethyol) was purchased from Pinnacle Biologics; 500-mg vials were reconstituted in $9.7 \mathrm{~mL}$ of saline. WR-1065 was kindly provided by the Drug Synthesis and Chemistry Branch, Division of Cancer Treatment, National Institutes of Health. L-lysine and bovine serum albumin (BSA) were obtained from Sigma.

\section{Animal Experiments}

Animal studies were conducted in accordance with the guidelines of the Animal Welfare Committee at Erasmus MC. Male Lewis rats were purchased from Harlan.

Two weeks after subcutaneous inoculation of approximately $10^{6}$ CA20948 tumor cells in both flanks of the rats, biodistribution studies were performed in 6 groups of 4 animals. Four groups received $15 \mu \mathrm{g}$ and 2 groups $0.5 \mu \mathrm{g}$ of ${ }^{111}$ In-DOTA,Tyr ${ }^{3}$-octreotate intravenously via the penis vein. Amifostine $(50 \mathrm{mg}, \sim 200$ $\mathrm{mg} / \mathrm{kg}$ ) or saline was administered $30 \mathrm{~min}$ before radiolabeled octreotate (preinjection) or immediately before radiolabeled octreotate via 2 routes: intravenously via the tail vein or subcutaneously (coinjection). After $24 \mathrm{~h}$, tumors, kidneys, and other organs were collected, weighed, and counted for radioactivity. Uptake was expressed as percentage of injected activity per gram of tissue. Results obtained for amifostine-treated rats were expressed as percentage of data obtained in control rats.

\section{In Vitro BN-16 and CA20948 Cell Assays}

Rat yolk sac carcinoma epithelial (BN-16) cells were kindly provided by Prof. Pierre J. Verroust, Department of Anatomy, University of Aarhus, Denmark (13). Uptake of $3 \cdot 10^{-3} \mathrm{M}$ ${ }^{99 \mathrm{~m}} \mathrm{Tc}$-HSA was determined after 1 -h incubation to verify megalin expression, as previously described (14). Then, uptake of $10^{-9} \mathrm{M}^{111} \mathrm{In}$-DOTA, Tyr ${ }^{3}$-octreotate in both BN-16 (megalin ${ }^{+}$, $\mathrm{sst}^{-}$) and CA20948 (megalin ${ }^{-}, \mathrm{sst}^{+}$) cells was tested, without or with addition of $10^{-4} \mathrm{M}, 10^{-3} \mathrm{M}$, or $10^{-2} \mathrm{M}$ amifostine, WR1065 , or lysine. An excess of BSA (10 mg/well) or octreotide $\left(10^{-5} \mathrm{M}\right)$ was added as a specificity control. Uptake was expressed as percentage of added activity per milligram of cellular protein $(\% \mathrm{~A} / \mathrm{mg})$. Control values were set at $100 \%$, and results of coincubation with the different agents were expressed as a percentage thereof. At least 2 experiments were performed in triplicate.

\section{Statistics}

Data were expressed as mean $\pm \mathrm{SD}$. Statistical analyses were performed using a Student $t$ test. Values of $P$ less than 0.05 were considered to be significantly different.

\section{RESULTS}

${ }^{111}$ In-DOTA,Tyr ${ }^{3}$-octreotate biodistribution was studied with 0.5 and $15 \mu \mathrm{g}$ of peptide, to simulate diagnostic and therapeutic application of radiolabeled octreotate. To label the therapeutic dose of $555 \mathrm{MBq}$ of ${ }^{177} \mathrm{Lu}$ for PRRT in rats (3), $15 \mu \mathrm{g}$ of DOTA, $\mathrm{Tyr}^{3}$-octreotate is required, whereas $0.5 \mu \mathrm{g}$ of peptide leads to optimal uptake in sst-expressing tissues (Table 1) (15). The effects of coadministration of amifostine were primarily examined using $15 \mu \mathrm{g}$ of ${ }^{111} \mathrm{In}$ DOTA, $\mathrm{Tyr}^{3}$-octreotate, applying 3 methods of administration (Fig. 2). A 39\% reduction of the renal retention of ${ }^{111}$ In-DOTA, Tyr $^{3}$-octreotate was found using subcutaneous injection of amifostine, whereas intravenous co- or preinjection of amifostine resulted in $62 \%$ and $61 \%$ reduction of renal retention, respectively. On the other hand, intravenous coinjection of amifostine with only $0.5 \mu \mathrm{g}$ of ${ }^{111}$ In-DOTA, Tyr $^{3}$-octreotate resulted in a mere renal uptake reduction of $27 \%$. Concerning sst-mediated uptake, amifostine coadministration with $15 \mu \mathrm{g}$ of ${ }^{111} \mathrm{In}$-DOTA, $\mathrm{Tyr}^{3}$-octreotate caused no significant effect on CA20948 uptake of ${ }^{111}$ In-DOTA, Tyr ${ }^{3}$-octreotate, but an almost 2fold increase of radioactivity in the pancreas, adrenals, and stomach was detected. This latter phenomenon was also found using $0.5 \mu \mathrm{g}$ of peptide ${ }^{111} \mathrm{In}$-DOTA, Tyr ${ }^{3}$ octreotate, but in this case a $48 \%$ reduction of tumor uptake was encountered.

Next, in vitro studies were performed using $\mathrm{BN}-16$ cells in which a specific ${ }^{99 m}$ Tc-HSA uptake of $20.6 \pm$ $1.2 \% \mathrm{~A} / \mathrm{mg}$ confirmed high megalin expression (data not 
TABLE 1

Biodistribution of ${ }^{111}$ In-DOTA, Tyr ${ }^{3}$-Octreotate in CA20948 Tumor-Bearing Rats at 24 Hours After Injection $(n=4)$

\begin{tabular}{lcc}
\hline \multicolumn{1}{c}{ Tissue } & $0.5 \mu \mathrm{g}$ & $15 \mu \mathrm{g}$ \\
\hline Kidney & $6.85 \pm 0.45$ & $8.54 \pm 1.46^{\star}$ \\
CA20948 & $7.62 \pm 1.48$ & $1.65 \pm 0.33^{\dagger}$ \\
Pancreas & $8.27 \pm 0.87$ & $0.99 \pm 0.06^{\dagger}$ \\
Adrenals & $9.00 \pm 1.91$ & $1.15 \pm 0.09^{\dagger}$ \\
Stomach & $1.29 \pm 0.20$ & $0.14 \pm 0.01^{\dagger}$ \\
& \\
\hline${ }^{*}$ Not significant; $P=0.07$. & \\
${ }^{\dagger} P<0.0001$. & \\
Data are mean \pm SD expressed as percentage of injected \\
activity per gram of tissue.
\end{tabular}

shown). Uptake of ${ }^{111}$ In-DOTA, Tyr ${ }^{3}$-octreotate was $0.7 \pm$ 0.1 in $\mathrm{BN}-16$ cells and $13.5 \pm 0.8 \% \mathrm{~A} / \mathrm{mg}$ in sst2-positive CA20948 cells. This uptake could be inhibited by an excess of BSA or octreotide, respectively (Fig. 3). Moreover, a significant inhibition of ${ }^{111} \mathrm{In}$-DOTA, $\mathrm{Tyr}^{3}$-octreotate uptake in $\mathrm{BN}-16$ cells was exerted in a dose-dependent way by WR-1065 (to $55.0 \% \pm 7.8 \%$ ) and amifostine (to $65.9 \% \pm 6.3 \%$ ) using $10^{-2} \mathrm{M}$, comparable to the inhibitory effects of $10^{-2} \mathrm{M}$ lysine and BSA. No significant competitive effects of amifostine or WR-1065 on ${ }^{111} \mathrm{In}$-DOTA, $\mathrm{Tyr}^{3}{ }^{3}$-octreotate uptake were found in CA20948 cells.

\section{DISCUSSION}

Previously, we described the ability of amifostine to protect rat kidneys from radiation damage after a 35- to 70-Gy absorbed radiation dose to the kidneys induced by ${ }^{177} \mathrm{Lu}$-DOTA, $\mathrm{Tyr}^{3}$-octreotate (3). Mitigation of radiationinduced nephrotoxicity seemed to be reached by sustaining a protective level of the active amifostine metabolite WR-1065 in the kidneys during the first week after therapy (9). Besides this radioprotective effect, we now speculate that, in addition, WR-1065 could act as a competitor in the charge-dependent megalin-mediated renal reabsorption of radiolabeled octreotate. Our theory is based on the currently identified reduction of uptake of ${ }^{111} \mathrm{In}$ DOTA, $\mathrm{Tyr}^{3}$-octreotate in rat kidneys in vivo and in $\mathrm{BN}-16$ cells in vitro in the presence of amifostine or WR-1065. This phenomenon is also known for the positively charged lysine, which resembles WR-1065 at the N-terminal end $(2,3)$.

Administered amifostine is rapidly cleared from the blood; within 6-30 min only $6 \%-10 \%$ of the drug remains, whereas after 5-10 min the maximum levels of WR-1065 are reached in the liver and kidneys $(10,16)$. This peak of WR-1065 occurs later after subcutaneous than after intravenous administration of amifostine (16), possibly explaining the lower level of reduction of renal uptake we found after subcutaneous administration. In the literature, initially the intravenous route was recommended for amifostine, but

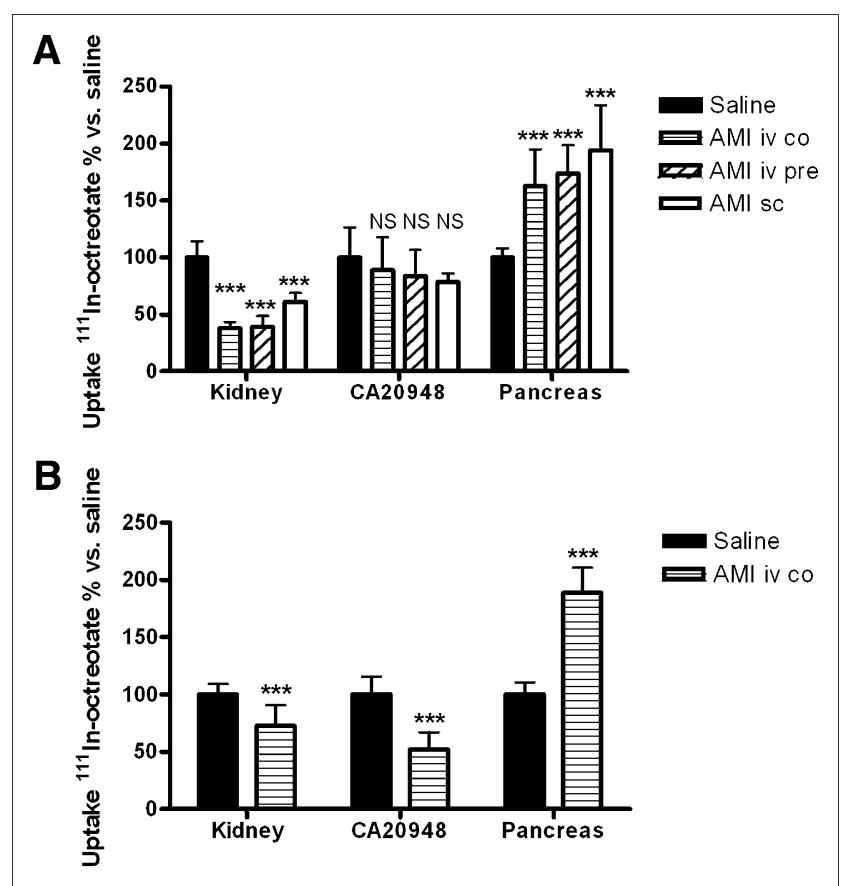

FIGURE 2. Biodistribution of $15 \mu \mathrm{g}(\mathrm{A})$ or $0.5 \mu \mathrm{g}(\mathrm{B})$ of ${ }^{111} \mathrm{In}$ DOTA, Tyr $^{3}$-octreotate $(3 \mathrm{MBq})$ in CA20948 tumor-bearing rats with coadministration of saline or amifostine $(200 \mathrm{mg} / \mathrm{kg})$ via different routes of injection at $24 \mathrm{~h}$ after administration $(n=4)$. Uptake was calculated as percentage of injected activity per gram of tissue, and value of the saline group was set at $100 \%$. Uptake values obtained in amifostine groups were expressed as percentage of control values $\pm \mathrm{SD}$. ${ }^{* \star \star} P<0.0001$ vs. saline group. Differences between renal uptake using $15 \mu \mathrm{g}$ of ${ }^{111} \mathrm{In}$ DOTA, Tyr $^{3}$-octreotate in amifostine sc group vs. amifostine iv co and amifostine iv pre were significantly different as well $(P<$ 0.0001 and $P=0.0002$, respectively). AMI iv co $=$ intravenous coinjection of amifostine with ${ }^{111} \mathrm{In}$-DOTA, Tyr ${ }^{3}$-octreotate; amifostine iv pre $=$ intravenous injection of amifostine 30 min before ${ }^{111}$ In-DOTA, Tyr ${ }^{3}$-octreotate; amifostine sc = subcutaneous injection of amifostine immediately before ${ }^{111} \mathrm{In}$-DOTA, Tyr ${ }^{3}$-octreotate; NS = not significant.

the need for exact timing, transient hypotension occurring in approximately $50 \%$ of cases, and side effects such as nausea and vomiting complicated incorporation into clinical practice (17). The more easily applied and better-tolerated subcutaneous route appeared to result in a comparable radioprotection efficacy after external-beam irradiation (18). Likewise, in rats similar cytoprotective effects were found using intraperitoneal, intravenous, or subcutaneous administration of amifostine at $200 \mathrm{mg} / \mathrm{kg}$ before or after 6-15 Gy of irradiation $(8,19)$.

Further improvement of kidney protection from ${ }^{177} \mathrm{Lu}-$ DOTA, $\mathrm{Tyr}^{3}$-octreotate may be reached by the combination of lysine and amifostine, to achieve both short-term reduction of renal radioactivity and long-term renal function protection. Because either an additive or a competitive effect for megalin may occur, the examination of the optimal timing and route of administration of both agents are important. 


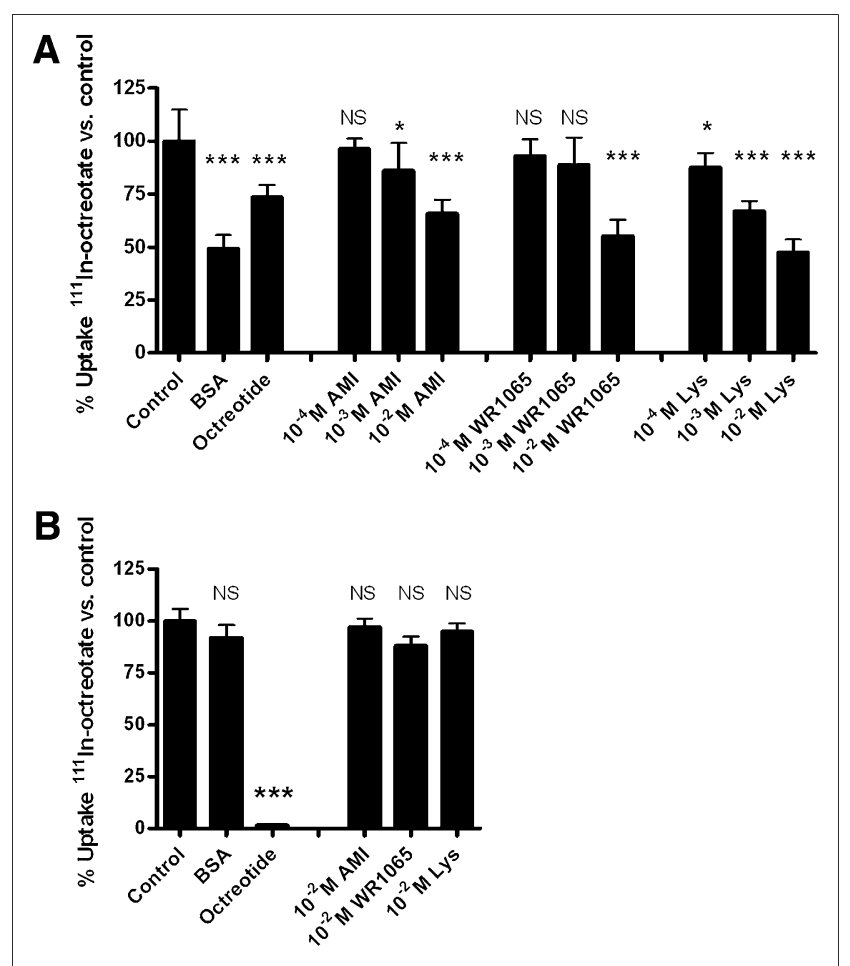

FIGURE 3. In vitro uptake of $10^{-9} \mathrm{M}^{111}$ In-DOTA,Tyr ${ }^{3}$-octreotate in megalin-expressing $\mathrm{BN}-16$ cells (A) or sst-expressing CA20948 cells $(B)$, without or with addition of $\left(10^{-4} \mathrm{M}, 10^{-3} \mathrm{M}\right.$ or) $10^{-2} \mathrm{M}$ amifostine, WR-1065, or lysine. Ten milligrams per well of BSA or $10^{-5} \mathrm{M}$ octreotide were added as specificity controls to $\mathrm{BN}-16$ and CA20948 cells, respectively. Control values were set at $100 \%$, and effects of coincubation with different agents were expressed as percentage vs. control values $\pm \mathrm{SD}$. ${ }^{\star} P<0.05$. ${ }^{\star \star \star} P<0.0001$ vs. control. AMI = amifostine; Lys $=$ lysine; NS = not significant.

The potential risk of undesired tumor protection by amifostine is being discussed since cotreatment was started (10). Here, we describe unaffected in vivo tumor uptake of $15 \mu \mathrm{g}$ of ${ }^{111} \mathrm{In}$-DOTA, Tyr $^{3}$-octreotate in rats with coadministered amifostine, which is in agreement with unaltered in vitro uptake of ${ }^{111}{ }^{1 n}$-DOTA, Tyr ${ }^{3}$ octreotate by CA20928 tumor cells coincubated with amifostine and WR-1065. Our results fit with recent metaanalyses concluding that amifostine did not compromise the antitumor efficacy of chemotherapy and radiotherapy $(4,20)$.

The striking observation that amifostine coadministration increased uptake of ${ }^{111} \mathrm{In}$-DOTA, Tyr $^{3}$-octreotate in sst-expressing normal organs may partially be explained by an earlier described transient drop in systolic blood pressure induced by a bolus injection of amifostine (17). The blood pressure was not registered, but hypotension would result in a prolonged circulation time of ${ }^{111} \mathrm{In}$ DOTA, $\mathrm{Tyr}^{3}$-octreotate and reduced blood supply to the subcutaneously developed tumors. These effects may have led to increased uptake in, for example, the radioinsensitive pancreas but a decreased CA20948 uptake using the optimal $0.5 \mu \mathrm{g}$ of ${ }^{111} \mathrm{In}$-DOTA, $\mathrm{Tyr}^{3}$-octreotate amount for high tumor uptake (15). Differences in receptor saturation and turnover rate of the receptor or peptide complex between tumors and normal tissues may be the reason for this discrepancy.

Besides kidney protection, administration of amifostine during PRRT might also accomplish radioprotection of bone marrow, the other organ at risk in patients $(1,6)$. Thus, application of amifostine might enable a safe increase of therapeutic radiation doses by PRRT to improve cure rates of this promising therapy.

\section{CONCLUSION}

Coadministration of the cytoprotector amifostine with radiolabeled octreotate reduced its renal uptake. This effect appears to be partially based on inhibition of the megalin-mediated renal reabsorption of radiopeptides by amifostine or its active metabolite WR-1065. Interference with tumor uptake was not detected in vitro and in vivo in rats during therapeutic conditions. Therefore, amifostine may be applied to provide kidney protection during PRRT both to reduce the radiation absorbed dose to the kidney and to prevent late development of radiation-induced renal fibrosis.

\section{DISCLOSURE STATEMENT}

The costs of publication of this article were defrayed in part by the payment of page charges. Therefore, and solely to indicate this fact, this article is hereby marked "advertisement" in accordance with 18 USC section 1734.

\section{ACKNOWLEDGMENTS}

Drs. Flavio Forrer, Cristina Müller, and Edgar Rolleman contributed to fruitful discussions. Technical assistance by Dr. Monique de Visser, Linda van der Graaf, Erik de Blois, and other technicians of the Department of Nuclear Medicine, Erasmus MC, was greatly appreciated. This study was supported by the Dutch Cancer Foundation grant no. EMCR 2007-3758. No other potential conflict of interest relevant to this article was reported.

\section{REFERENCES}

1. Kwekkeboom DJ, de Herder WW, van Eijck $\mathrm{CH}$, et al. Peptide receptor radionuclide therapy in patients with gastroenteropancreatic neuroendocrine tumors. Semin Nucl Med. 2010;40:78-88.

2. Melis M, Krenning EP, Bernard BF, et al. Localisation and mechanism of renal retention of radiolabelled somatostatin analogues. Eur J Nucl Med Mol Imaging. 2005;32:1136-1143.

3. Rolleman EJ, Forrer F, Bernard B, et al. Amifostine protects rat kidneys during peptide receptor radionuclide therapy with $\left[{ }^{177} \mathrm{Lu}\right.$-DOTA0,Tyr3]octreotate. Eur J Nucl Med Mol Imaging. 2007;34:763-771.

4. Winczura P, Jassem J. Combined treatment with cytoprotective agents and radiotherapy. Cancer Treat Rev. 2010;36:268-275.

5. De Souza CA, Santini G, Marino G, et al. Amifostine (WR-2721), a cytoprotective agent during high-dose cyclophosphamide treatment of nonHodgkin's lymphomas: a phase II study. Braz J Med Biol Res. 2000;33: 791-798. 
6. Hensley ML, Hagerty KL, Kewalramani T, et al. American Society of Clinical Oncology 2008 clinical practice guideline update: use of chemotherapy and radiation therapy protectants. J Clin Oncol. 2009;27:127-145.

7. Shaw LM, Bonner H, Lieberman R. Pharmacokinetic profile of amifostine. Semin Oncol. 1996;23:18-22.

8. Kaldir M, Cosar-Alas R, Cermik TF, et al. Amifostine use in radiation-induced kidney damage: preclinical evaluation with scintigraphic and histopathologic parameters. Strahlenther Onkol. 2008;184:370-375.

9. Capizzi R. Amifostine: the preclinical basis for broad-spectrum selective cytoprotection of normal tissues from cytotoxic therapies. Semin Oncol. 1996; $23: 2-17$.

10. Shaw LM, Bonner HS, Brown DQ. Metabolic pathways of WR-2721 (ethyol, amifostine) in the BALB/c mouse. Drug Metab Dispos. 1994;22:895-902.

11. Koukourakis MI. Amifostine: is there evidence of tumor protection? Semin Oncol. 2003;30:18-30.

12. Breeman WA, De Jong M, Visser TJ, et al. Optimising conditions for radiolabelling of DOTA-peptides with ${ }^{90} \mathrm{Y},{ }^{111} \mathrm{In}$ and ${ }^{177} \mathrm{Lu}$ at high specific activities. Eur J Nucl Med Mol Imaging. 2003;30:917-920.

13. Le Panse S, Verroust P, Christensen EI. Internalization and recycling of glycoprotein 280 in BN/MSV yolk sac epithelial cells: a model system of relevance to receptor-mediated endocytosis in the renal proximal tubule. Exp Nephrol. 1997;5:375-383.

14. Vegt E, Eek A, Oyen WJ, et al. Albumin-derived peptides efficiently reduce renal uptake of radiolabelled peptides. Eur J Nucl Med Mol Imaging. 2010;37:226-234.

15. de Jong M, Breeman WA, Bernard BF, et al. Tumour uptake of the radiolabelled somatostatin analogue [DOTA0, TYR3]octreotide is dependent on the peptide amount. Eur J Nucl Med. 1999;26:693-698.

16. Bachy CM, Fazenbaker CA, Kifle G, et al. Tissue levels of WR-1065, the active metabolite of amifostine (Ethyol), are equivalent following intravenous or subcutaneous administration in cynomolgus monkeys. Oncology. 2004;67:187-193.

17. Bukowski RM. Amifostine (Ethyol): dosing, administration and patient management guidelines. Eur J Cancer. 1996;32A:S46-S49.

18. Kouvaris JR, Kouloulias VE, Vlahos LJ. Amifostine: the first selective-target and broad-spectrum radioprotector. Oncologist. 2007;12:738-747.

19. Cassatt DR, Fazenbaker CA, Kifle G, Bachy CM. Subcutaneous administration of amifostine (ethyol) is equivalent to intravenous administration in a rat mucositis model. Int J Radiat Oncol Biol Phys. 2003;57:794-802.

20. Sasse AD, Clark LG, Sasse EC, Clark OA. Amifostine reduces side effects and improves complete response rate during radiotherapy: results of a meta-analysis. Int J Radiat Oncol Biol Phys. 2006;64:784-791. 